\title{
A Design of Supplementary Controller for UPFC to Improve Damping of Inter-Area Oscillations
}

\author{
Angshuman Khan*, Uttam Narendra Thakur \\ Department of Electronics \& Communication Engineering, University of Engineering \& Management, Jaipur, Rajasthan \\ 303807, India
}

Corresponding Author Email: angshuman.khan@uem.edu.in

https://doi.org/10.18280/jesa.540212

Received: 30 November 2020

Accepted: 16 March 2021

\section{Keywords:}

controller, damping, lead lag compensator, oscillation, pulse width modulation, unified power flow controller, UPFC

\begin{abstract}
The conventional highly composite and interrelated power systems sometimes consist of thousands of buses and hundreds of alternators, which need improvement in electric power consumption, consistency maintains, and security. To meet the ever-growing good quality power demand, the improvement of conventional transmission methods and the formation of new concepts that might allow the optimum utilization of accessible power with no reduction of system reliability are of the utmost importance. But due to high complexity, these system responses are oscillatory in nature. If this system oscillation is damped somehow such that the system achieves a new steady operating condition within the transient period, then the system becomes stable. A stable power system requires that the system oscillations should die immediately. This paper proposed a novel control strategy based on a lead-lag based stable controller for a unified power flow controller (UPFC) for faster damping of inter-area oscillations of the system. Each design has been successfully simulated in MATLAB Simulink platform.
\end{abstract}

\section{INTRODUCTION}

It is well known that one of the major interests in the power system is to find out proper stability conditions by mitigating the power system oscillations. One widespread way to alleviate the oscillations of the power system is the use of FACTS devices. FACTS is the acronym of Flexible Alternating Current Transmission System and it is generally introduced to improve the power transmission capability of the system. There are many FACTS devices with their advantages and disadvantages. However, a unified power flow controller (UPFC) is a very popular FACTS device due to its ability to control multiple parameters [1]. It is worth mentioning, several efforts have been made before but the introduction of UPFC has always been the first choice for its many advantages which include better control capability along with multiple parameter control ability. There exist many such good designs in literature and till now it an interesting research topic in electrical engineering. A methodical approach to design UPFC based controllers that help the oscillations to die out has been proposed by Tambey and Kothari [2]. Active power flow control by regulating voltage magnitudes of UPFC has been discussed by Padiyar and Kulkarni [3]. Proper modeling of both dynamic and steady-state of UPFC has been analyzed by Nabavi-Niakiand and Iravani [4] to understand its impact on thesystem. Fuzzy based UPFC controllers have very fruitful results and transient analysis using this has been noticed by Mohanty et al. [5]. Albatsh et al. [6] validated the dynamic power flow control using fuzzy logic for UPFC. Extenuation of sub-synchronous resonance with proportional control for UPFC has been demonstrated by Raju et al. [7] and space vector-based analysis has been done successfully by Zhang et al. [8]. Modern neural network-based UPFC for the supplementary controller has been designed by Tsai et al. [9]. UPFC based partial linearization controller has been proposed by Parvathy et al. [10] and the self-tuning fuzzy controller for UPFC has been optimized by Ahmadi et al. [11] recently. Similarly, many more kinds of research are going on UPFC controllers as an important FACTS device and the supplementary controller is one of them [12, 13].

It is mentioned in the popular book by Ogata [14] a few years back that a linear suitable model of a power system network together with UPFC is helpful for different smallsignal studies and also for designing the damping controller. This is a key statement in the research of UPFC designs and our current research also followed it. UPFC block is placed between two buses called sending bus (S) and receiving bus (R). The rms phasor voltage of sending bus is $\bar{V}_{S}$ and the same for receiving bus is $\bar{V}_{R}$. The phase angle between $\bar{V}_{S}$ and $\bar{V}_{R}$ is known as power angle $(\delta)$. It is worth to mention that the active power component $(\mathrm{P})$ is directly proportional to $\delta$ and the reactive power component $(\mathrm{Q})$ is directly proportional to the change in voltage magnitude $(\Delta V)$. In this article, a discussion has been carried out on the dynamic model of the UPFC including a couple of proposals of control strategies. The slip speed of machine $\Delta \omega$ is taken as the input to the controller. Amongst numerous models of UPFC, the pulse width modulation (PWM) based model with the proposed control strategy has been used for simulation here. This part is represented using a simple block diagram as shown in Figure 1 to facilitate easy understanding. Pm and Pref are the actual value and reference value of active power respectively, similarly, Qm and Qref are the actual value and the reference value for reactive power respectively. 


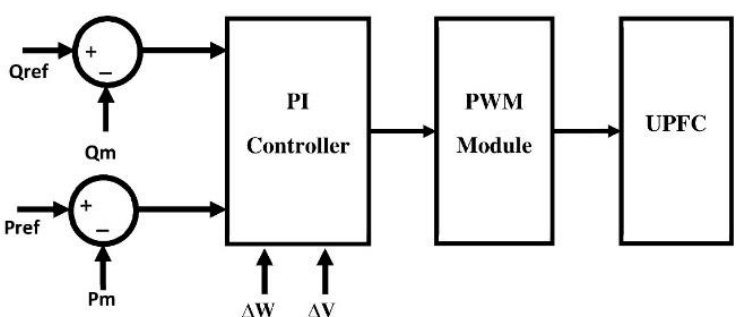

Figure 1. Simple block representation of PWM based UPFC

\section{PULSE WIDTH MODULATION TECHNIQUE}

A little discussion on PWM is necessary to illustrate our research work. The sinusoidal PWM technique is applied to generate triggering pulses for gate turn-off thyristors (GTOs) [15]. Here a reference sinusoid named $\mathrm{v}_{\mathrm{r}}$, with a magnitude of $A_{r}$ is compared with another carrier signal, named $v_{c}$. This carrier signal is sawtooth in nature and having a magnitude of $A_{c}$ as shown in Figure 2. The switching frequencies of GTOs are defined by the frequencies of the sawtooth wave. First, consider Figure 3, which is a phase-arm network.

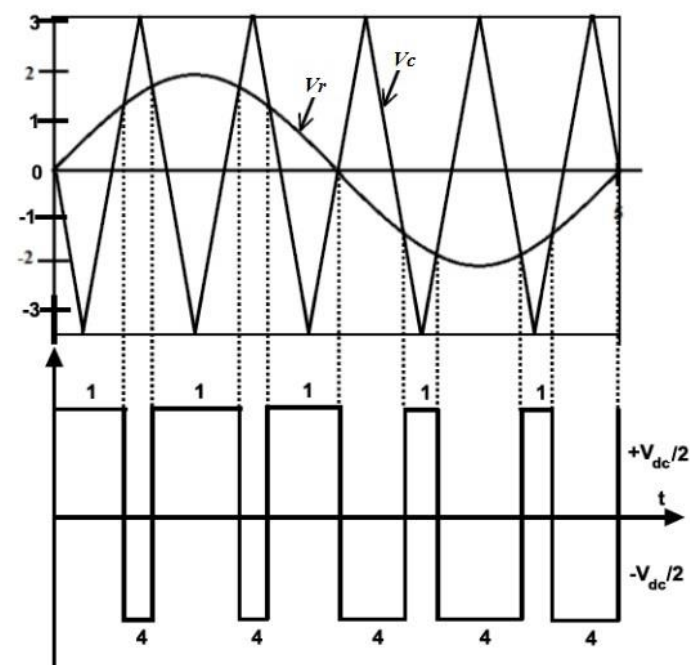

Figure 2. Sinusoidal PWM technique

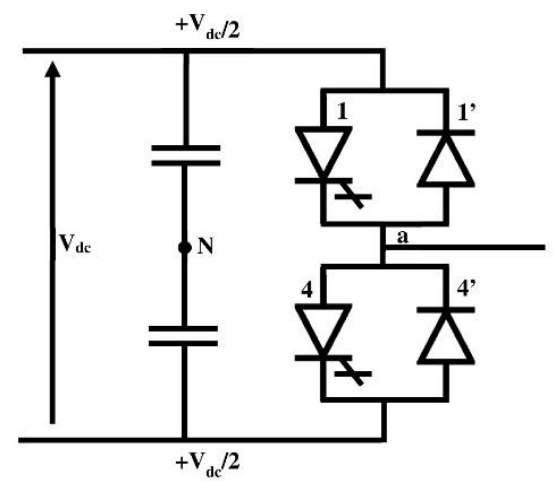

Figure 3. A phase leg of VSC

In the network, if $v_{r}>v_{c}$ then turn on the pulse for device 1 and turn off pulse for device 4 are generated and the condition $v_{r}<v_{c}$ generates turn off pulse for device_1 and turn on the pulse for device_4.
The reference signal frequency eventually determines the fundamental frequency of the output signal of the converter. The duration of the gate pulses can be controlled by varying the reference signal amplitude. The ratio of $A_{r}$ and $A_{c}$ indicates the amplitude modulation index denoted as $\mathrm{m}$.

$$
\mathrm{m}=A_{r} / A_{c}
$$

When $m \leq 1$ the peak amplitude of the converter output's primary component is expressed as follows:

$$
\mathrm{V}=\mathrm{m} \frac{V_{d c}}{2}
$$

This sinusoidal PWM waveform is shown in Figure 2 and a phase-arm of VSC is shown in Figure 3. Our proposed model is based on the PWM technique.

\section{OPERATION OF UPFC}

As we know, the optimum location of the UPFC device is the midpoint of the transmission line [16]. Figure 4 shows the fundamental power system model with UPFC. The basic model of UPFC consists of double voltage sourced converters (VSC), which are connected with a common DC link connection as shown in Figure 4. Here $\mathrm{S}$ is the sending bus and $\mathrm{R}$ is the receiving bus. The rms phasor voltage of sending bus is $\bar{V}_{S}=V_{S}<\delta_{S}$ and the rms phasor voltage of receiving bus is $\bar{V}_{R}=V_{R}<\delta_{R}$. The voltage drop between the sending and receiving bus is denoted as $\bar{V}_{P Q}$. The sending end of VSC is connected in shunt mode and hence called a shunt converter. There is another VSC known as the series converter, connected in series with the transmission line. As the basic UPFC model includes power electronics devices and it works on very high voltage lines, it requires a step-down transformer to bring the high voltages to the allowable range [17]. With proper implementation of pulse width modulation to generate the triggering pulses for the switching devices of converters, obtained as mentioned below. The shunt and series injected voltage can be expressed as:

$$
\begin{gathered}
V_{S H}=m_{S H} \frac{V_{d c}}{2 \sqrt{2 n_{S H} V_{B}}} \\
V_{S E}=m_{S E} \frac{V_{d c}}{2 \sqrt{2 n_{S E} V_{B}}}
\end{gathered}
$$

where, $m_{S H}$ is amplitude modulation index for the shunt converter control signal, $m_{S E}$ is amplitude modulation index for the series converter control signal, $n_{S H}$ is turns ratio of shunt transformer, $n_{S E}$ is turns ratio of the series transformer, $V_{B}$ is the base voltage of the system in $\mathrm{kV}, V_{d c}$ is a common DC link voltage in $\mathrm{kV}$.

$\bar{V}_{S H}$ and $\bar{V}_{S E}$ are expressed in terms of magnitude and phase as:

$$
\begin{gathered}
\bar{V}_{S H}=V_{S H}<\delta_{S H}=V_{S H}<\left(\delta_{S}-\varphi_{S H}\right) \\
\bar{V}_{S E}=V_{S E}<\delta_{S E}=V_{S E}<\left(\delta_{S}-\varphi_{S E}\right)
\end{gathered}
$$

where, $\varphi_{S H}$ is the firing angle of the shunt converter and $\varphi_{S E}$ is the firing angle of the series converter considering the sending bus voltage as reference phasor. 


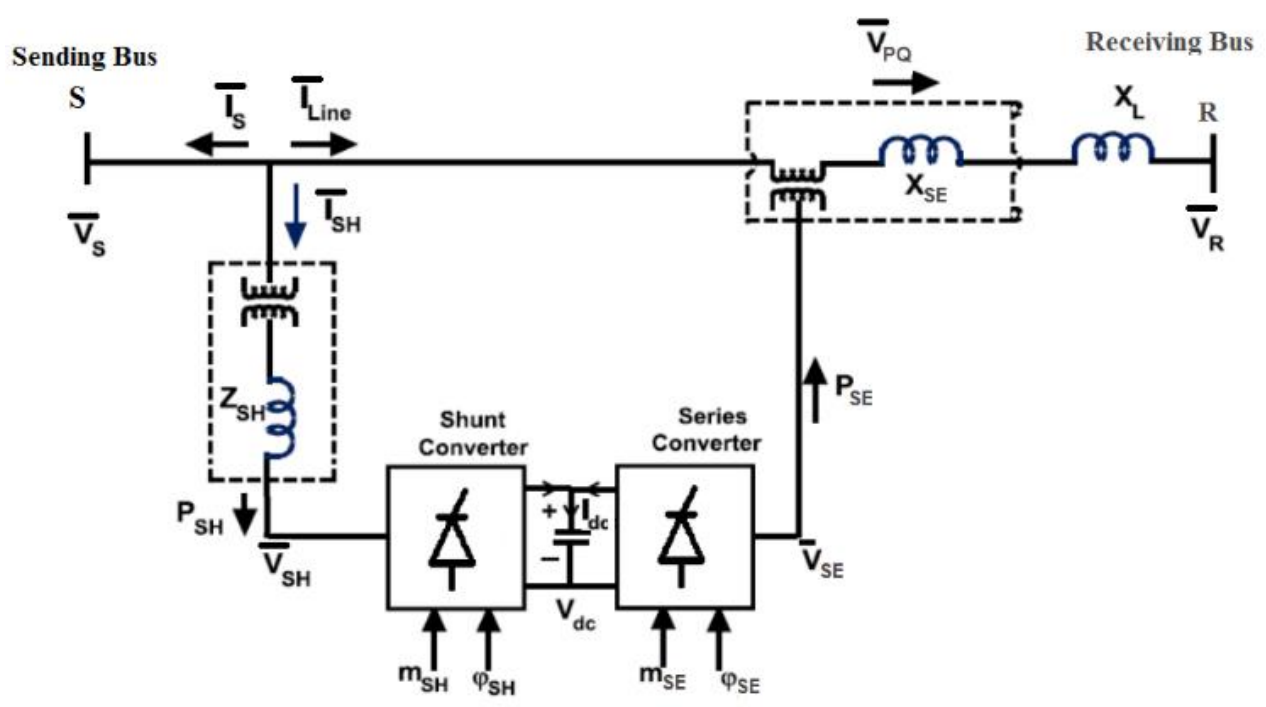

Figure 4. Fundamental system model with UPFC

In Figure 4, the sending bus current is mentioned as $\bar{I}_{S}$ and the line current is denoted as $\bar{I}_{\text {Line }}$; it is clear that $\bar{I}_{S}=-\bar{I}_{S H}-$ $\bar{I}_{\text {Line }}$, where $\bar{I}_{S H}$ is shunt current. UPFC is a mixture of static synchronous compensator (STATCOM) and a static synchronous series compensator (SSSC) where STATCOM and SSSC are coupled via a common dc link. The shunt and series converters can work as both STATCOM and SSSC to control reactive components of current as well as a voltage that is to be injected in shunt and series correspondingly [18]. The real power supplied to the shunt converter is denoted as $P_{S H}$ and the real power demanded by the series converter is denoted by $P_{S E}$ as shown in Figure 4. Between the AC terminals, the active power flow is possible in either direction, but reactive power wouldn't flow via DC link. Hence it has to be consumed or produced locally by both converters. The purpose of shunt VSC is to exchange the reactive power within the AC system which eventually provides the self-regulating shunt compensation for the transmission line. To initiate a shunt reactive current, the injected shunt voltage can be manipulated. This manipulation keeps the sending end bus voltage at its pre-fixed value, called automatic voltage control mode.

\section{PROPOSED DESIGN}

The linearized model of power network with UPFC is used for different cases like small-signal analysis of the system and to design the additional damping regulator design $[18,19]$. We used the bus system modeling technique and searched the effect on stability for three-phase systems [20-22]. This linearized model has been derived as follow:

$$
\dot{x}=A x+B u
$$

where, $x$ is the state vector, $\dot{x}$ is the derivative of the state vector and the control vector is denoted as $u$.

$$
x=\left[\begin{array}{lllll}
\Delta \delta & \Delta \omega & \Delta E_{q}{ }^{\prime} & \Delta E_{f d} & \Delta v_{d c}
\end{array}\right]^{T}
$$

We know that the state vector column matrix as it derived from the transpose of a row matrix. In Eq. (6), $\delta$ is torque angle and $\omega$ is rotor speed of the generator, $E_{q}^{\prime}$ is generator terminator voltage, $E_{f d}$ is generator field voltage and $v_{d c}$ is dc-link capacitor voltage of the UPFC.

$$
u=\left[\begin{array}{lllll}
\Delta u_{p s s} & \Delta m_{e} & \Delta \delta_{e} & \Delta m_{b} & \Delta \delta_{b}
\end{array}\right]^{T}
$$

Again the control matrix is a column matrix as it is derived from the transpose of the row matrix. The components of this matrix are $\Delta u_{p s s}, m_{e}, \delta_{e}, m_{b}$ and $\delta_{b}$, where, $\Delta u_{p s s}$ which is the damping signal, $m_{e}$ is the modulation index of shunt converter voltage, $\delta_{e}$ is the phase angle of shunt converter voltage, $m_{b}$ is the modulation index of series converter voltage, $\delta_{b}$ is the phase angle of the series inverter voltage. The system matrices $A$ and control matrix $B$ are given as:

$$
\begin{gathered}
A=\left[\begin{array}{ccccc}
0 & \omega_{b} & 0 & 0 & 0 \\
-\frac{K_{1}}{M} & -\frac{D}{M} & -\frac{K_{2}}{M} & 0 & -\frac{K_{p d}}{M} \\
-\frac{K_{4}}{T_{d 0}^{\prime}} & 0 & -\frac{K_{3}}{T_{d 0}^{\prime}} & \frac{1}{T_{d 0}^{\prime}} & -\frac{K_{q d}}{T_{d 0}^{\prime}} \\
-\frac{K_{A} K_{5}}{T_{A}} & 0 & -\frac{K_{A} K_{6}}{T_{A}} & -\frac{1}{T_{A}} & -\frac{K_{A} K_{v d}}{T_{A}} \\
K_{7} & 0 & K_{8} & 0 & -K_{9}
\end{array}\right] \\
B=\left[\begin{array}{ccccc}
0 & 0 & 0 & 0 & 0 \\
0 & -\frac{K_{p e}}{M} & -\frac{K_{p \delta_{E}}}{M} & -\frac{K_{p b}}{M} & -\frac{K_{p \delta_{B}}}{M} \\
0 & \frac{K_{q e}}{T_{d 0}^{\prime}} & -\frac{K_{q \delta_{E}}}{T_{d 0}^{\prime}} & -\frac{K_{q b}}{T_{d 0}^{\prime}} & -\frac{K_{q \delta_{B}}}{T_{d 0}^{\prime}} \\
\frac{K_{A}}{T_{A}} & -\frac{K_{A} K_{v e}}{T_{A}} & -\frac{K_{A} K_{v} \delta_{e}}{T_{A}} & -\frac{K_{A} K_{v b}}{T_{A}} & -\frac{K_{A} K_{v \delta_{B}}}{T_{A}} \\
0 & K_{c e} & K_{c \delta_{E}} & K_{c b} & K_{c \delta_{B}}
\end{array}\right]
\end{gathered}
$$

Clearly, from this linearized model, $\Delta \omega$ can be a control signal to control $m_{e}, \delta_{e}, m_{b}$ and $\delta_{b}$, any variations of these parameters are represented using the symbol $\Delta$. Here in this work, the speed deviation signal of machine one $(\Delta \omega)$ is fed to the lead-lag based damping controller which gives the output signal $\Delta V_{d}, \Delta V_{q}$ which further calibrate $m_{b}$ and $\delta_{b}$. 


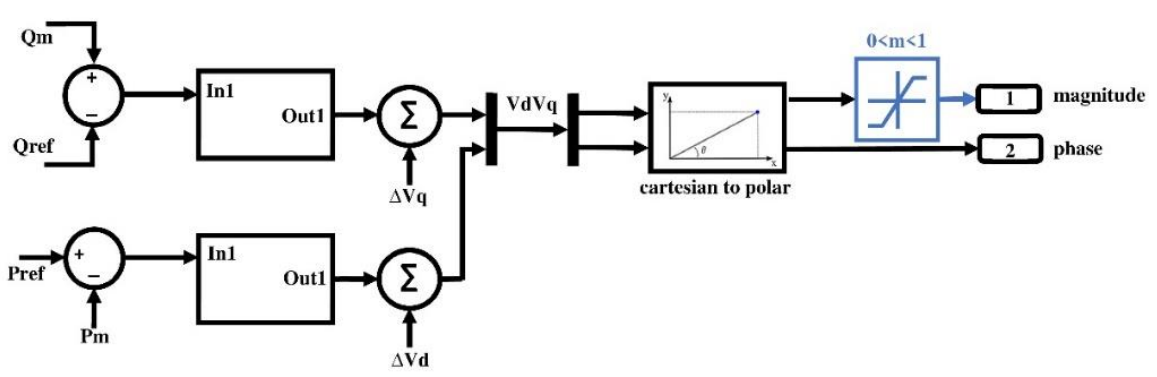

(a) Additional damping signal with PI controller

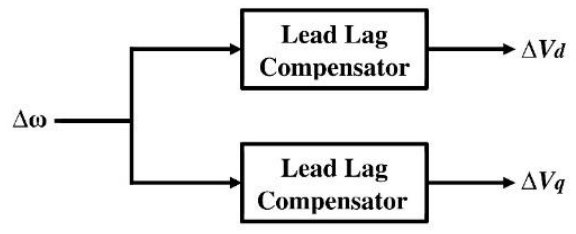

(b) Simple block representation of damping controller

Figure 5. PI controller based active and reactive power controller

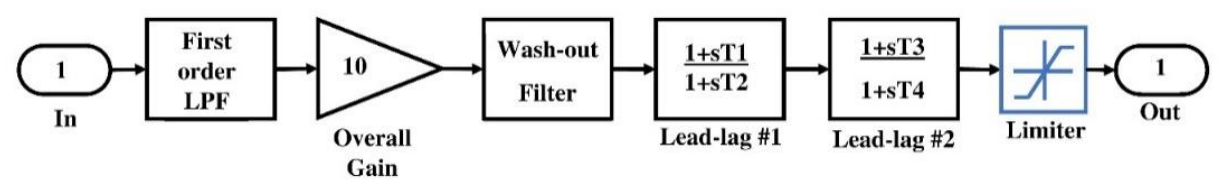

Figure 6. Simulation block of damping controller

The arrangement of the proposed controller with PI controller is shown in Figure 5. The first block is of a low pass filter of the time constant $T_{\mathrm{s}}=0.03$ which removes the highfrequency oscillations in the signal which is the input for the damping controller. Then the signal is multiplied with a gain of 10. The next block is a washout filter which is basically a high pass filter having a property of rejecting steady-state inputs i.e. if there is any dc offset value in the signal that part is removed by the filter. The next two blocks are the most essential parts of the controller used for frequency stabilization. The first block is a lead compensator that adds a positive phase angle to the system at high frequencies, which enhances the sensitivity and stability of the proposed system. And lag compensator adds a negative phase angle to the system at low frequencies which reduces the steady-state error. The parameter values of the lead-lag compensator are $\mathrm{T} 1=0.05$, $\mathrm{T} 2=0.02, \mathrm{~T} 3=3, \mathrm{~T} 4=5.4$. A model of the simulation block is shown in Figure 6 which was implemented in MATLAB to assign the appropriate cut-off frequency. There is a possibility of change in output if the input signals are passed unchanged and it is worth mentioning that the input signals are associated with oscillations. The lowpass filter is used to attenuate the higher frequency components. The cut-off frequency of the LPF has been kept near to the fundamental frequency. Next, the amplifier with a gain of 10 increases the power of the incoming signal. The washout filter is a highpass filter and the cut-off frequency has been kept near the middle point frequency range. This filter is important as it resists the steady change in input which block to modify the output. The value of the washout time constant is not important for the lead-lag compensator and it may vary between $1 \mathrm{~s}$ to $20 \mathrm{~s}$. The two-stage of lead-lag block is a phase compensator that gives the suitable phase-lead characteristics and it compensates input-output the phase lag.

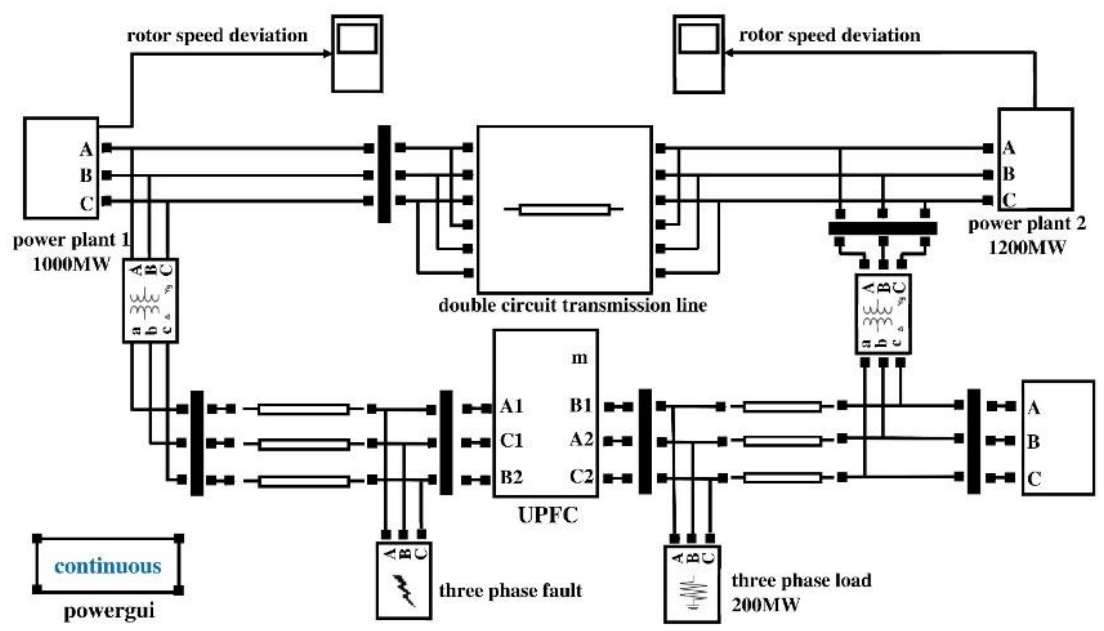

Figure 7. Proposed design in MATLAB tool 


\section{SIMULATION RESULTS AND DISCUSSION}

In this project, a two-machine infinite bus system model has been simulated in MATLAB (shown in Figure 7). The effect on the stability of the system for three-phase fault and sudden load variation has also been studied. To improve the stability UPFC has been introduced in the transmission line.

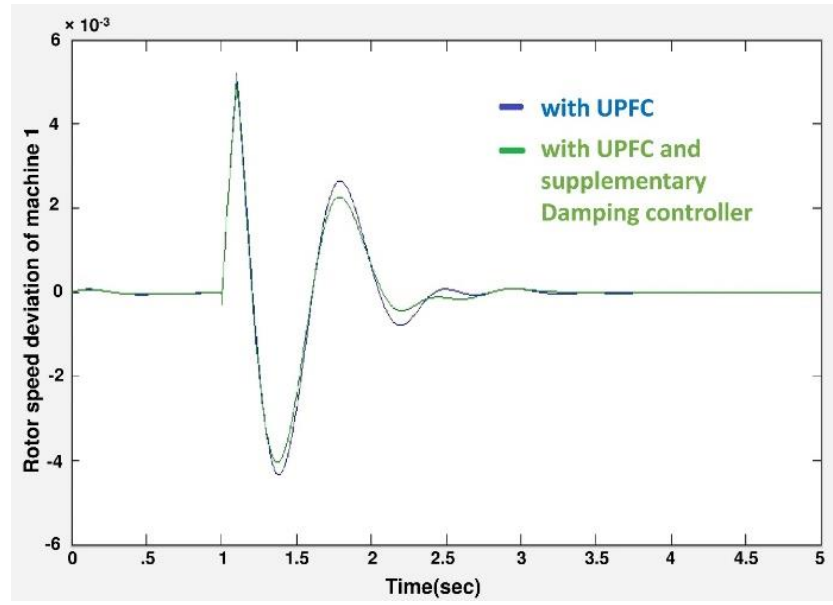

Figure 8. Rotor speed deviation of machine 1 for transient fault with a duration of $0.1 \mathrm{sec}$

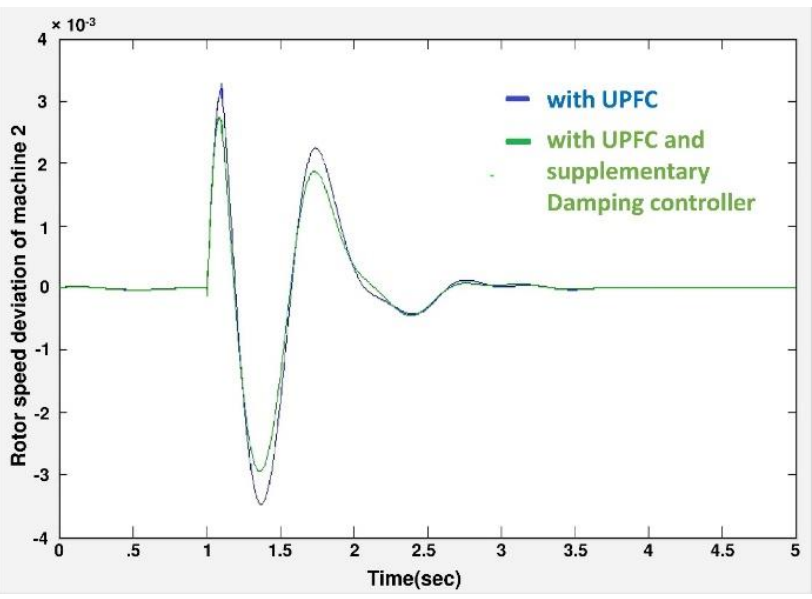

Figure 9. Rotor speed deviation of machine 2 for transient fault with a duration of $0.1 \mathrm{sec}$

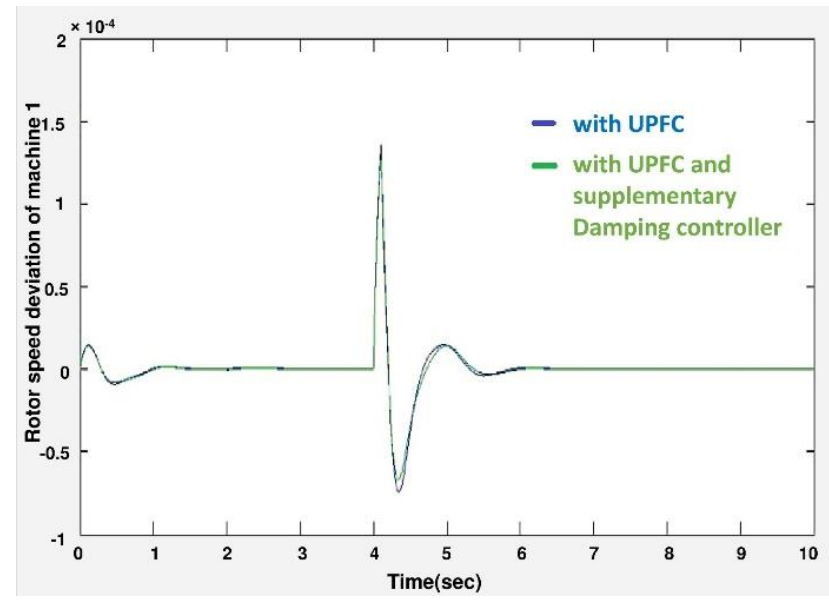

Figure 10. Rotor speed deviation of machine 1 for sudden load variation

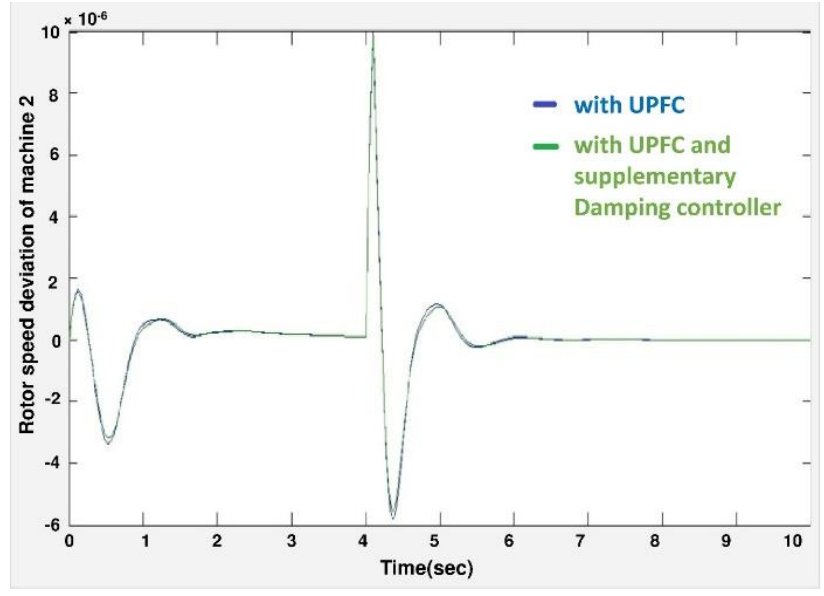

Figure 11. Rotor speed deviation of machine 2 for sudden load variation

First, the model is run without having a three-phase fault and without UPFC connected. The active power measured and got the value as $587 \mathrm{MW}$, whereas the reactive power also measured, which is -27 MVAR. Then a three-phase severe fault is introduced for a duration of 0.1 seconds. After the fault is nullified, both the parameters, i.e. the active and reactive power (i.e. $587 \mathrm{MW}$ and -27 MVAR respectively) have to be maintained properly to achieve synchronism quickly for the machines in the system. This is the main purpose to introduce UPFC at the load bus, and after this step stability settlement of the system has been realized. Then the three-phase fault block is eliminated and an abrupt load discrepancy of $50 \mathrm{MW}$ is introduced for $0.1 \mathrm{sec}$. The rotor speed deviation of machine 1 and machine 2 for transient fault are shown in Figure 8 and Figure 9 respectively, where a three-phase severe fault is introduced for 0.1 seconds duration. The rotor speed deviation of machine 1 and machine 2 for sudden load variation are shown in Figure 10 and Figure 11 respectively.

\section{CONCLUSIONS}

In this paper, the damping controller has been proposed and performance has been compared with the state of art PI controller used in the series inverter of UPFC. Two cases of disturbances have been introduced first and then the system behavior has been studied. The two types of disturbances introduced as a three-phase fault of duration $0.1 \mathrm{sec}$ and another are sudden load variation of $100 \mathrm{MW}$ in double machines infinite bus system. Rotor speed deviation of two machines has been considered as the parameter to investigate system performance. The main objective is to make this deviation zero with the designed controller, as fast as possible after the disturbances are cleared. It has been noticed that system performance is improved when the supplementary damping controller has used with UPFC the results for both the cases of transient disturbances. With regards to UPFC's capability in the improvement of transient stability and damping low-frequency oscillation (LFO) of power system a PI controller and a lead-lag compensator based supplementary controller has been presented. Simulations are performed for two cases of transient disturbances and the effectiveness of the proposed controller has been observed. Simulation results for all the cases indicated that UPFC due to its unique capability of controlling both real and reactive power can be effectively used to control rotor angle oscillations in the power system 
during various disturbances and it is further beneficial with the additional supplementary damping controller, designed based on lead-lag compensator.

\section{ACKNOWLEDGMENT}

The authors would like to thank Sudip Halder, Department of Electrical Engineering, Visvesvaraya National Institute of Technology (VNIT Nagpur) for his kind help, valuable suggestions and continuous support to complete this work

\section{REFERENCES}

[1] Amara, S., Hsan, H.A. (2012). Power system stability improvement by FACTS devices: A comparison between STATCOM, SSSC and UPFC. 2012 First International Conference on Renewable Energies and Vehicular Technology, Hammamet, pp. 360-365. https://doi.org/10.1109/REVET.2012.6195297

[2] Tambey, N., Kothari, M.L. (2011). Damping of power system oscillations using an advanced unified power flow controller. IEE Proceedings-Generation, Transmission and Distribution, 150(2): 129-140. https://doi.org/10.1049/ip-gtd:20030114

[3] Padiyar, K.R., Kulkarni, A. (1998). Control design and simulation of unified power flow controller. IEEE Transactions on Power Delivery, 13(4): 1348-1354. https://doi.org/ 10.1109/61.714507

[4] Nabavi-Niaki, A., Iravani, M. (1996). Steady-state and dynamic models of unified power flow controller (UPFC) for power system studies. IEEE Transactions on Power Systems, 11(4): 1937-1943. https://doi.org/10.1109/59.544667

[5] Mohanty, A., Patra, S., Ray, P.K. (2016). Robust fuzzysliding mode based UPFC controller for transient stability analysis in autonomous wind-diesel-PV hybrid system. IET Generation, Transmission \& Distribution, 10(5): $\quad 1248-1257 . \quad$ https://doi.org/10.1049/ietgtd.2015.1000

[6] Albatsh, F.M., Mekhilef, S., Ahmad, S., Mokhlis, H. (2017). Fuzzy-logic-based UPFC and laboratory prototype validation for dynamic power flow control in transmission lines. IEEE Transactions on Industrial Electronics, $\quad 64(12)$ : 9538-9548. https://doi.org/10.1109/TIE.2017.2711546

[7] Raju, D.K., Umre, B.S., Junghare, A.S., Babu, B.C. (2017). Mitigation of subsynchronous resonance with fractional-order PI based UPFC controller. Mechanical Systems and Signal Processing, 85: 698-715. https://doi.org/10.1016/j.ymssp.2016.09.012

[8] Zhang, J., Dorrell, D.G., Li, L., Guo, Y. (2018). Decoupling controller design and controllable regions analysis for the space vector modulated matrix converterunified power flow controller in transmission systems. Electric Power Components and Systems, 46(1): 1-14. https://doi.org/10.1080/15325008.2018.1431818

[9] Tsai, H.C., Liu, J.H., Chu, C.C. (2019). Integrations of neural networks and transient energy functions for designing supplementary damping control of UPFC. IEEE Transactions on Industry Applications, 55(6):
6438-6450. https://doi.org/10.1109/TIA.2019.2936381

[10] Parvathy, S., Thampatty, K.S., Nambiar, T.P. (2020). Design and implementation of partial feedback linearization controller for unified power flow controller. Electric Power Systems Research, 187: 1-11, https://doi.org/10.1016/j.epsr.2020.106438

[11] Ahmadi, S., Haghighi, D.A., Kheyrdoust, M., Dini, F., Nasim, K. (2020). The application of optimum selftuning fuzzy logic controllers in multi-area power systems including UPFC. IEEE 18th World Symposium on Applied Machine Intelligence and Informatics (SAMI), Herlany, Slovakia, 2020: 187-194. https://doi.org/10.1109/SAMI48414.2020.9108721

[12] Sivakumar, T.A., Linda, M.M. (2020). Improving the dynamic performance of grid connected wind farms using modern UPFC. Microprocessors and Microsystems, 74: 1-14. https://doi.org/10.1016/j.micpro.2020.103015

[13] Hatnapure, H.B., Chandrakar, V.K. (2017). Power quality improvement by using UPFC. 2nd International Conference for Convergence in Technology (I2CT), Mumbai, pp. 1014-1017. https://doi.org/10.1109/I2CT.2017.8226282

[14] Ogata, K. (1997). Modern Control Engineering. 3rd ed. Upper Saddle River, NJ: Prentice-Hall

[15] Al-Qallaf, S.A., Al-Mawsawi, S.A., Haider, A. (2014). Comparison of fundamental frequency model and PWM based model of UPFC. International Scholarly and Scientific Research \& Innovation, 8(10): 1592-1595. https://doi.org/10.5281/zenodo.1096439

[16] Hingorani, N.G., Gyugyi, L. (2000). FACTS concept and general system considerations. Understanding FACTS: Concepts and Technology of Flexible AC Transmission Systems, pp. 1-35. https://doi.org/10.1109/9780470546802.ch1

[17] Gyugyi, L. (1992). Unified power-flow control concept for flexible AC transmission systems. IEE Proceedings C (Generation, Transmission and Distribution), 139(4): 323-331. https://doi.org/10.1049/ip-c.1992.0048

[18] Cañizares, C.A., Uzunovic, E., Reeve, J. (2006). Transient stability and power flow model of the unified power flow controller for various control strategies. International Journal of Energy Technology and Policy, 4(3-4): 349-378. https://doi.org/10.1504/IJETP.2006.009978

[19] Adware, R.H., Jagtap, P.P., Helonde, J.B. (2010). Power system oscillations damping using UPFC damping controller. 3rd International Conference on Emerging Trends in Engineering and Technology, GOA, pp. 340344. https://doi.org/10.1109/ICETET.2010.167

[20] Singh, B., Al-Haddad, K., Chandra, A. (1998). A new control approach to three-phase active filter for harmonics and reactive power compensation. IEEE Transactions on Power Systems, 13(1): 133-138. https://doi.org/10.1109/59.651624

[21] Kundur, P. (2006). Power System Stability and Control. McGraw -Hill Inc. New York.

[22] Gupta, V. (2010). Study and effects of UPFC and its control system for power flow control and voltage injection in a power system. International Journal of Engineering Science and Technology, 2(7): 2558-2566. 